\title{
Os Primórdios da Psicanálise e a insuficiência do descritivismo
}

\section{The beginnings of psychoanalysis and the insufficiency of descriptivism}

\section{Los comienzos del psicoanálisis y la insuficiencia del descriptivismo}

\author{
Samira Pontes* \\ Universidade Federal de São J oão del Rei - UFSJ, São J oão del Rei, Minas Gerais, \\ Brasil
}

\section{Roberto Calazans**}

Universidade Federal de São J oão del Rei - UFSJ, São J oão del Rei, Minas Gerais, Brasil

\begin{abstract}
RESUMO
A problemática perpassada neste trabalho refere-se ao questionamento, a partir da Psicanálise, da insuficiência do postulado descritivista que orienta a nosografia psiquiátrica do Manual Diagnóstico e Estatísticos de Transtornos Mentais (DSM), no que tange ao estabelecimento de um diagnóstico diferencial. Buscamos, nos textos pré-psicanalíticos de Freud, demonstrar que em seu esforço inicial de sistematização teórica e clínica, o autor já apontava a insuficiência de uma nosografia sintomática meramente descritiva, uma vez que a descrição pura dos sinais e sintomas de uma patologia não permite uma articulação inteligível, entre aquilo que se apresenta como fenômeno clínico, e os aspectos estruturais. Apresentamos também as formulações iniciais sobre a psicose, evidenciando o esforço freudiano no sentido de uma sistematização de seu diagnóstico diferencial. Se é no âmago das distinções das estruturas clínicas que se opera um diagnóstico diferencial, o descritivismo inviabiliza sua articulação ao promover a descaracterização das diferenças estruturais.
\end{abstract}

Palavras-chave: psicanálise, descritivismo, diagnóstico diferencial.

\section{ABSTRACT}

The issue that permeates this paper refers to the investigation, based on a psychoanalytic perspective, of the descriptivist's insufficient that guides the nosography psychiatric, of the Diagnostic and Statistical Manual of Mental Disorders (DSM), in regard to the establishment of a differential diagnosis. We seek to demonstrate, in Freud's pre-psychoanalytic writings, that in his initial effort of theoretical and clinical systematization, the author has pointed out the inadequacy of a merely descriptive symptomatic nosography, since the pure description of the signs and symptoms of a condition doesn't allow an intelligible articulation between what presents itself as a phenomenon and the structural aspects. We also present the 
initial formulations of psychosis, showing Freud's effort towards a systematization of its differential diagnosis. If it's at the center of the distinctions of clinical structures that operates a differential diagnosis, the descriptivism prevents this articulation while promoting mischaracterization of structural differences.

Keywords: psychoanalysis, descriptivism, differential diagnosis.

\section{RESUMEN}

La cuestión transcurrida en este trabajo se refieren al cuestionamiento, desde el psicoanálisis, de lo fracaso del descriptivismo que guía la nosografia psiquiátrica do Manual Diagnóstico y Estadístico de los Trastornos Mentales (DSM), en relación con el establecimiento de un diagnóstico diferencial. Buscamos en los escritos pre-psicoanalíticos de Freud demuestrar que en su esfuerzo de sistematización teórica y clínica, el autor ha señalado la insuficiencia de una nosografía sintomática meramente descriptivo, ya que la pura descripción de los signos y síntomas de una condición no permite una articulación inteligible entre lo que se presenta como un fenómeno clínico y los aspectos estructurales. Presentamos también las formulaciones iniciales de la psicosis, que muestra el esfuerzo de Freud hacia una sistematización de su diagnóstico diferencial. Si es en el corazón de las distinciones de estructuras clínicas que se opera un diagnóstico diferencial, el descriptivismo impide la articulación, mientras que promueve la caracterización errónea de las diferencias estructurales

Palabras clave: psicoanálisis, descriptivismo, diagnóstico diferencial.

\section{Introdução}

A questão proposta no presente artigo - a insuficiência do postulado descritivista na teoria freudiana - está circunscrita ao campo de problemáticas que se referem à psicopatologia. Desse modo, optamos por definir, brevemente, o que é a psicopatologia. Tomando como referência Álvarez, Esteban e Sauvagnat (2004) em seu livro Fundamentos de Psicopatogía Psicoanalítica, o objeto da psicopatologia é a investigação e a explicação das diversas manifestações do mal-estar psíquico, do pathos subjetivo. A psicopatologia deve se encarregar dos aspectos semiológicos (estudo dos sinais e sintomas observados); patogênicos (mecanismos do "adoecer" e as reações à patologia) e etiológicos (causas e aspectos desencadeantes da patologia); bem como dos aspectos nosológicos (definição e delimitação das patologias) e nosográficos (descrição e classificação das patologias) (p. 23).

Entretanto, nos últimos anos, uma "versão espúria da psicopatologia", parafraseando os autores, foi elaborada com a intenção de reduzi-la a uma suposta semiologia com base em "conceitos operacionais". Trata-se do Manual Diagnóstico e Estatístico de Transtornos Mentais (DSM). Publicado pela Associação Americana de Psiquiatria (APA), o DSM é o dispositivo oficial de diagnósticos psiquiátricos nos Estados Unidos, sendo utilizado em grande escala no mundo. Por mais que o estatuto não-psicopatológico do DSM já 
tenha sido destacado por Tucker (1998), na edição do DSM-IV-TR realizada em 2000, os revisores são categóricos ao afirmarem que apostam no manual como " um instrumento didático para o ensino da psicopatologia" (APA, 2002, p. 21). Essa pretensão é reafirmada no DSM-V: "trata-se de uma ferramenta para clínicos, um recurso essencial para a formação de estudantes" (APA, 2014, p. 1). Ou seja, não podemos deixar de pontuar que é em relação à psicopatologia que esse manual se coloca, pretendendo influenciar tanto na formação de profissionais quanto na organização de serviços de saúde mental.

O DSM, principalmente a partir de sua terceira versão em 1980, foi elaborado com a pretensão de ser um instrumento científico e principalmente a-teórico de diagnóstico. Sob a égide de se criar uma linguagem psicopatológica comum, a perspectiva era de que esse manual conseguisse ultrapassar as diversas teorias que constituem o campo da psicopatologia, de modo a unificar os sistemas diagnósticos no campo do sofrimento psíquico. O DSM se assenta no descritivismo. Ao privilegiar o que se procura compreender como sinais de objetividade incontestável, o DSM se esforça em contornar qualquer reflexão teórica (Álvarez, Esteban \& Sauvagnat, 2004).

O DSM, juntamente com a Classificação Internacional de Doenças (CID), são as diretrizes diagnósticas - ou sua lógica, ao menos utilizadas pelo Sistema Único de Saúde (SUS) para realizar estudos epidemiológicos e estabelecer o financiamento para a rede de saúde mental. Analisá-los, então, não deixa de ter uma importância epistêmica e política.

Isto posto, a problemática que perpassa este trabalho refere-se ao questionamento, a partir do referencial psicanalítico, da insuficiência do postulado descritivista que orienta a nosografia psiquiátrica atual do DSM e determina os sistemas classificatórios ditos "hegemônicos", como a CID-10, na abordagem clínica-diagnóstica, principalmente no estabelecimento de um diagnóstico diferencial.

Desse modo, buscamos, a partir do Volume I das Obras Completas de Freud, demonstrar que, em seu esforço inicial de sistematização teórica e clínica, já havia uma insuficiência de uma nosografia sintomática meramente descritiva, principalmente no que se refere ao estabelecimento de um diagnóstico diferencial, uma vez que a descrição pura dos sinais e sintomas de uma patologia não permite uma articulação inteligível entre aquilo que se apresenta como fenômeno clínico e os aspectos estruturais. Como apontam Sadala e Martinho (2011) Freud não utilizou com frequência o termo estrutura e nem mencionou a expressão estruturas clínicas; contudo, estes estão implícitos em sua obra desde os seus primórdios no que tange à importância do diagnóstico diferencial para a condução da análise.

É importante esclarecer que o questionamento aqui desenvolvido não se refere apenas ao ato de descrição dos sinais e sintomas de uma 
doença, uma vez que enxergamos o lugar de importância da semiologia na construção de uma teoria psicopatológica. O que apontamos como problemático é uma psicopatologia restrita a uma semiologia, que se esgota no plano descritivo dos sinais e sintomas dos fenômenos clínicos. Eis aqui um fator complicador quando estamos lidando com a clínica e o sujeito em seu sofrimento psíquico. Pretendemos demonstrar, a partir de Freud e o ineditismo da Psicanálise, que o descritivismo semiológico puro e "ingênuo" inviabiliza o estabelecimento de um diagnóstico diferencial que oriente a prática clínica.

Além da crítica feita pela Psicanálise, sobre a qual pretendemos evidenciar neste artigo, também podemos situar algumas reflexões importantes no próprio campo da psiquiatria contemporânea em relação à insuficiência de uma nosografia meramente descritivista proposta pelo DSM. No editorial do British Journal of Psychiatry, por exemplo, Stangellini e Broome (2014) assentuam a importância do estudo da psicopatologia para que a prática da clínica psiquiátrica possa sobrepujar os ditames nosográficos. Destacam-se também as reflexões epistemológicas de Aragona (2009a, 2009b, 2014) sobre o papel da comorbidade na crise do sistema classificatório do DSM. Partindo de uma perspectiva kuhniana, a comorbidade é analisada pelo autor como uma anomalia na estrutura do DSM e sua proposta perpassa a necessidade de repensar o paradigma da psiquiatria descritivista. Juan López-Ibor Jr e María-Inés López-Ibor (2008) apostam em uma abordagem antropológica para a nosografia psiquiátrica atual ao atentarem para o fato de que a classificação baseada na manifestação fenomênica de sinais e sintomas do DSM não problematiza a origem desses sintomas e seu significado para a pessoa.

Amplamente conhecidas também foram as críticas de Allen Frances, presidente da força-tarefa responsável pela revisão do DSM-IV-TR. Frances tornou-se um dos maiores críticos do desenvolvimento do DSM-V e as consequências dos critérios inconsistentes de diagnóstico baseados na nosografia psiquiátrica desse manual. Em seus livros Saving Normal (2013) e Somos todos enfermos mentales? (2014), Frances aborda o aumento excessivo de números de diagnóstico, a criação de falsas epidemias de transtornos mentais e a relação intrínseca da indústria farmacêutica ao processo de medicalização da normalidade.

Há de se destacar também o Movimento Internacional Stop-DSM lançado em 2011 e o alcance do debate proposto pelos organizadores. O Stop-DSM é uma iniciativa coordenada pelas associações Espai Freud de Barcelona e Forum ADD de Buenos Aires, cuja pauta perpassa o questionamento da lógica classificatória do DSM, defendendo, em contrapartida, uma abordagem subjetiva e clínica do sofrimento psíquico. Esse movimento contou com a 
elaboração de manifestos de cinco países participantes (I tália; Argentina, França, Espanha e Brasil) com objetivo comum de apontar para outra prática diagnóstica além do DSM. Os manifestos foram organizados em um livro por Émile Jalley e publicado na França: Six Manifestes Contre le Manuel Diagnostique et Statistique des Troubles Mentaux (2011).

Mesmo diante de tais críticas amplamente divulgadas, a publicação da quinta edição do DSM em 2013 trouxe-nos uma nova oportunidade para discussão dos seus pressupostos epistemológicos e as consequências de seu uso clínico. Além disso, o Instituto Nacional de Saúde Mental dos Estados Unidos (NIMH) reintroduz a validade desse debate quando anunciou que irá se afastar do financiamento de pesquisas baseadas nas categorias diagnósticas do DSM ao propor um novo projeto de pesquisa diagnóstica dos transtornos mentais: o Research Domain Criteria: RDoC (Insel, 2013). Fundamentada numa abordagem biogenética e nas evidências da neurociência. o RDoC pretende criar um novo sistema de classificação. Em outras palavras, o DSM, tomado como ícone da psiquiatria descritiva, já não responde mais ao curso do progresso científico (Zorzanelli, Dalgalarrondo \& Banzato, 2014).

Situadas as críticas, ressaltamos que nossa proposta neste artigo é apontar para outra dimensão da crítica ao postulado descritivista partindo, então, do referencial psicanalítico. Acreditamos que a nosografia baseada no postulado descritivista, como proposta no DSM, já encontra seu aspecto insuficiente na orientação da prática clínica quando Freud ainda estava às voltas com os primórdios de sua teorização sobre os sintomas histéricos enigmáticos para o campo médico da época. Pretendemos mostrar a possibilidade de localização da insuficiência do descritivismo - catalogação de sinais e sintomas reduzidos apenas aos seus aspectos descritivos sem qualquer articulação causal-explicativa - no ineditismo mesmo da psicanálise.

\section{O Descritivismo e o paradigma nosográfico da psiquiatria descritiva do DSM}

O descritivismo é aqui definido como o uso da descrição com pretensões em ser minuciosa e pormenorizada dos sinais e sintomas de uma enfermidade, o trabalho semiológico isolado e desarticulado dos demais esforços teóricos que definem o que é uma psicopatologia, como exposto anteriormente. $O$ descritivismo garantiria a objetividade de um sistema classificatório, tal como é apregoado pelo DSM, por não ter a necessidade de "ceder" a um sistema teórico explicativo - daí a sua autodenominação "a-teórico". Contudo, o postulado descritivista é analisado antes como uma estratégia teórica que garante o não-pronunciamento das questões 
etiológicas do sofrimento psíquico, dissociando assim, a classificação nosológica de um esforço de teorização.

Berrios (2012a), em sua análise da estrutura conceitual da psicopatologia descritiva, nos mostra que ela não é propriamente uma novidade na psiquiatria: ela desenvolveu-se durante a primeira metade do século XIX. Desde então, a tarefa declarada da psicopatologia descritiva tem sido a classificação dos fenômenos clínicos. O descritivismo configurou-se, primeiramente, como uma linguagem descritiva, resultado de uma exigência que se impunha aos primeiros psiquiatras em relação à necessidade de se realizar bons registros clínicos.

Historicamente, Berrios (2012b) aponta que a necessidade de descrever de forma confiável os sinais e sintomas partiu de condições práticas e teóricas. Teoricamente, o postulado descritivista era uma exigência conceitual do modelo anatomoclínico da doença. Já no campo prático, novas necessidades descritivas surgiram quando houve um envolvimento gradual dos médicos em direção aos asilos, posto que, como médicos oficiais da instituição, eram legalmente intimados a manter bons registros clínicos. Como consequência dessa ênfase inicial na descrição de sinais e sintomas, deu-se a fragmentação de categorias clássicas, como a mania, a melancolia e a demência. As entidades psicopatológicas ganharam uma abordagem quantitativa, passando a ser definidas como um conjunto de sintomas elementares (Berrios, 2012b).

Contudo, foi com o psiquiatra alemão Emil Kraepelin que o descritivismo ganhou sistematização e tornou-se o eixo constituinte dos campos nosológicos e nosográficos da psiquiatria moderna. Como assinalam Dunker e Kyrillos Neto (2011), Kraepelin radicalizou a concepção falretiana ${ }^{1}$ de entidade mórbida, consolidando de forma definitiva a vocação nosológica da psicopatologia. Kraepelin considerava a doença mental como uma entidade mórbida subjacente aos moldes orgânicos. Seu método consistia primordialmente na observação, descrição minuciosa dos fenômenos clínicos e a posterior classificação. Desse modo, o sistema de classificação desenvolvido por Kraepelin baseava-se na sintomatologia, na evolução e no prognóstico de cada entidade clínica isolada.

O caráter categorial marca o sistema classificatório de Kraepelin: cada enfermidade deveria, descritivamente, se diferenciar de outras entidades mórbidas. Isto é, não haveria a ideia de uma gradação ou evolução de uma doença a outra. As manifestações psicopatológicas seriam explicitamente distintas, utilizando-se uma descrição minuciosa e pormenorizada como forma de operar essa distinção. Nesse sentido, os fatores etiológicos não ocupariam lugar de destaque em suas investigações, caracterizando-as mais como descritivas do que como explicativas. Como parte do projeto kraepeliano que atesta a "objetividade" do descritivismo na 
categorização dos processos mórbidos, Pereira (2001) acentua o esforço de Kraepelin de evitar qualquer interpretação da parte do paciente que viesse a interferir na objetividade do processo descritivo.

O caráter descritivo das investigações psicopatológicas de Kraepelin ainda apresenta ressonâncias na clínica psiquiátrica descritivista, influenciado as classificações norte-americanas, principalmente 0 DSM-III, DSMIII-R, DSM-IV, DSM - IV - TR e DSM-V:

Os integrantes da força tarefa que organizaram os últimos DSM se intitulam neokraepelianos. Assim como o DSM, Pessoti (1999) nos lembra que a classificação de Kraepelin prioriza a descrição de sintomas, e não a etiologia das doenças. Kraepelin desconsidera os processos psicodinâmicos, descrevendo apenas as causas endógenas e exógenas da loucura. (Kyrillos Neto, Silva, Pederzoli, \& Hernandes, 2011, p. 46).

O postulado descritivista ganhou novo fôlego com o advento do DSMIII, publicado em 1980, com a proposta de ser um instrumento diagnóstico universal, a-teórico e científico. Como forma de garantir uma suposta neutralidade teórica, o DSM-III recorreu a uma descrição minuciosa e exaustiva dos fenômenos patológicos. Com o descritivismo, temos a catalogação sistemática dos fenômenos patológicos que acaba por desconsiderar como e porque surgem, negligenciando, assim, a questão etiológica por excelência.

Podemos situar uma crítica em relação aos fatores culturais e sóciohistóricos desconsiderados pelos promotores do DSM em sua proposta de viabilizar uma ferramenta diagnóstica universal. Como exemplo, temos o Guia Latino-americano de Diagnóstico Psiquiátrico (2003), compilado pela Associação Psiquiátrica da América Latina. Embora este instrumento incorpore o modelo da Classificação Internacional das Doenças (CID), e também do DSM, constata-se que esses manuais não são "suficientes para refletir as maneiras idiossincráticas de experimentar uma enfermidade e as necessidades clínicas particulares da população latino-americana" (ALP, 2003, p. 8). Nesse sentido, Stagnaro (2007) lembra que a China tem seu próprio sistema diagnóstico e acentua, ironicamente, que o DSM-IV, em sua pretensão de ser mundial e hegemônico, deixa de lado um bilhão e meio de pessoas.

Mais do que uma característica do DSM, o descritivismo é uma estratégia utilizada para evitar pronunciar-se sobre a etiologia do sofrimento psíquico, valendo-se da recusa de qualquer sistema teórico. A recusa ao debate sobre a causalidade do sofrimento psíquico culminou também em uma mudança terminológica: abandona-se o conceito de doença mental, por este exigir um marcador biológico como causalidade da patologia e adota-se, 
convenientemente, a noção de transtorno mental - conjunto de sinais e sintomas (síndromes) sem uma especificação etiológica.

A descrição minuciosa de sinais e sintomas, sem uma articulação inteligível entre eles, resulta numa diluição das entidades nosográficas. A partir de seus modelos puramente descritivistas de abordagem do sofrimento psíquico, os manuais estatísticos anulam e descaracterizam o par de diferenciação diagnóstica neurose-psicose, diluindo suas características em uma diversidade de transtornos "não mais diferenciais por sua estrutura, resposta ou modo de defesa, mas por ser uma síndrome que reúne sinais e sintomas específicos com uma duração específica de sua apresentação" (Resende e Calazans, 2013, p. 151).

No que tange ao diagnóstico diferencial, o descritivismo tem por função descaracterizar, no plano teórico, a diferenciação entre as estruturas clínicas. Além disso, com a noção de comorbidade, podemos ter diagnósticos os mais variáveis para um mesmo caso, reunindo muitas vezes categorias de sintomas contraditórios. A noção de comorbidade foi adotada no DSM-III-R, amplamente utilizada no DSM-IV e no DSM-V. Como resultado, tem-se a prevalência de duas ou mais categorias diagnósticas de eixos distintos no estabelecimento de um diagnóstico. Isto é, dois ou mais diagnósticos para o mesmo sujeito.

Desse modo, a perspectiva descritivista inviabiliza o estabelecimento de um diagnóstico diferencial. Afinal, quando estamos lidando com classificações e o manejo do sofrimento psíquico, qual a relevância de se estabelecer um diagnóstico diferencial que muitas vezes não se consegue com o mero descritivismo?

\section{A I mportância do diagnóstico diferencial}

Como resultado de nossas exposições anteriores, questionamos, então, o diagnóstico proveniente do reducionismo descritivo proposto pelo DSM, um diagnóstico que prioriza a mera descrição do fenômeno. Um instrumento diagnóstico, corroborado pelo uso da estatística como método primordial na abordagem da patologia, tem como decorrência a anulação do lugar por excelência do sujeito: a clínica. Nesta perspectiva, Oliveira e Neves (2012, p. 6) concluem que:

Assim, não são os métodos técnicos, o uso de números, a recorrência estatística e outros recursos matemáticos que irão garantir uma orientação diagnóstica. Por ser o sujeito consideravelmente distinto, tanto dos animais quanto das máquinas, será somente através de uma discussão sobre a estrutura do sujeito e sobre como ele exerce sua entrada na 
cultura, ou seja, como ele se inventa diante do mundo simbólico em que está inserido, é que poderemos pensar sobre a validade ou não de um diagnóstico.

Para abordarmos a relevância de um diagnóstico diferencial na prática clínica é necessário operar uma digressão em relação à distinção psicanalítica entre fenômeno e estrutura. Nesse sentido, é válido iniciar a proposta deste tópico retomando a afirmação de que fenômeno e estrutura não são noções correlatas às de sintoma e doença na clínica psiquiátrica. Conforme nos apontam Figueiredo e Tenório (2002_ p.33), a distinção entre síndrome e nosologia (sintomas e doença) não equivale à distinção entre fenômenos e estrutura, "porque mesmo o diagnóstico nosológico é fenomenológico e, seguindo uma tendência atual, cada vez mais 'sindrômico'" ( $p$. 33).

Como forma de promover uma aproximação com a noção de fenômeno e estrutura e sua diferenciação, recorreremos ao exemplo da psicose, desenvolvido por Soler (2007), que se insere nesse campo de problemáticas. Soler (2007) parte do texto de Lacan De uma questão preliminar a todo tratamento possível da psicose observando que a inclusão da psicose no campo da fala e da linguagem é situada por Lacan como parte do "aspecto do fenômeno" (p. 11), ou seja, daquilo que aparece. Nesse sentido, Soler (2007) reitera que, para Lacan, a foraclusão não é um fenômeno. Ela é antes um operador específico da psicose, uma hipótese de sua causalidade significante ou "um axioma que explica os fenômenos" (p. 12).

Qual a importância de se conceber a foraclusão como operador e não fenômeno da psicose, levando em consideração a problemática deste tópico - a questão diagnóstica? Se a foraclusão não faz parte do fenômeno, não é pela foraclusão que se diagnostica a psicose, escreve Soler (2007). Ou seja, o fenômeno, como aquilo que aparece, não é o ponto de partida para o estabelecimento de um diagnóstico diferencial. Essa afirmação já vai de encontro ao que estabelecem os manuais estatísticos de classificação: um diagnóstico a partir da mera descrição fenomênica.

Como afirma Lacan, a psicose comporta uma ordem, não no mesmo sentido neurótico, mas ainda assim não é uma desordem (Soler, 2007). Se o seu diagnóstico não deve se dar pelo o que aparece, o fenômeno, de onde a psicanálise propõe partir o estabelecimento de um diagnóstico diferencial? É aqui que apresentamos o lugar da estrutura.

Como definição, "uma estrutura é dada pela relação de alguns traços pertinentes entre si, que dispensam uma profusão fenomenológica" (Figueiredo e Tenório, 2002, p. 38). Desse modo, por "diagnóstico estrutural podemos entender como um diagnóstico que se dá a partir da fala dirigida ao analista, logo, sob transferência, onde os 
fenômenos vão se orientar com referência ao analista como um operador e não como pessoa" (Figueiredo e Machado, 2000, p. 67). Interessa mais à psicanálise conhecer as estruturas que tramam os fenômenos patológicos do que o movimento contrário. No estabelecimento de um diagnóstico diferencial, poderíamos falar em uma ruptura entre aquilo que se apresenta como fenômeno e a leitura estrutural do sujeito, ou seja, seu modo de funcionamento que diz da sua relação com a falta fundamental e a inserção na ordem simbólica.

O movimento da psiquiatria descritiva que amplia sua nosografia a cada nova edição de um manual, acarretando na invenção de novos transtornos, não "atinge" a orientação dada pela psicanálise na construção de um diagnóstico diferencial. Isto se deve ao fato de que, no campo psicanalítico, lidamos com o conceito de estrutura, o que equivale dizer de um ordenamento diante do discurso dominante da civilização que têm incidências apenas no "invólucro" do sintoma. A psicanálise aposta menos no surgimento de patologias criadas pelos diagnósticos descritivos e estatísticos e mais nas formas possíveis de amarração do sujeito na estrutura em si.

O diagnóstico em psicanálise apresenta dois pontos fundamentais, de acordo com Miller (1998). O destacamento de uma estrutura clínica só faz sentido se, além disso, considerarmos a localização subjetiva, ou seja, os modos como o sujeito se posiciona frente à função de seu sintoma em relação ao Outro da linguagem e do corpo. A partir dessa localização podem-se constituir as condições do sujeito encontrar outros meios de se haver com seu sofrimento. Podemos dizer que não há sentido no estabelecimento de um diagnóstico sem a consideração do sujeito em sua relação com o sintoma.

Como já afirmamos, o descritivismo tem por função descaracterizar, no plano teórico, a diferenciação entre as estruturas clínicas. Aí reside o desafio diagnóstico e clínico proposto pela psicanálise. Operar uma distinção diagnóstica é ultrapassar o olhar fenomênico e descritivo e ir em direção ao mais-além dos fenômenos. Encontramos no Seminário 3 (1955/1956) uma orientação de Lacan a respeito da análise do fenômeno na construção diagnóstica, acentuando a diferença radical entre a investigação diagnóstica psicanalítica e a fenomênica: "do ponto de vista que nos guia, não temos essa confiança a priori no fenômeno, pela simples razão de que nosso encaminhamento é científico, e de que o ponto de partida da ciência moderna é não se fiar nos fenômenos e procurar atrás algo de mais subsistente que o explique" (p.170). 


\section{Os Primórdios de Freud e a insuficiência do postulado descritivista}

O primeiro volume das Obras Completas de Freud é caracterizado por uma constante revisão conceitual que se apresenta em duas direções: uma relacionada aos constantes debates com 0 conhecimento psicopatológico da época, e outra, que nos interessa principalmente neste artigo, ao próprio esforço na busca de um diagnóstico diferencial que norteasse a clínica. Seus textos ditos 'prépsicanalíticos' remetem ao esforço inicial da construção de uma abordagem não descritivista do sofrimento psíquico. Como aponta Carvalho (2012, p. 239), "é justamente no âmbito da correspondência à Fliess que [...] se evidencia a tentativa de Freud de produzir uma escrita própria".

É inegável que no início de suas elaborações teóricas, Freud deparouse com inúmeros impasses no trabalho de se realizar um diagnóstico diferencial. Como assinala Leguil (1989), o ponto de partida de Freud na construção de sua teoria - a etiologia sexual das neuroses permitiu-Ihe desde o começo opor, pela primeira vez na clínica, a histeria e a obsessão, e desse modo, diferenciar a fobia e distinguir a psicose: "Freud não separa semiologia, psicopatologia e terapêutica, porém, por meio de sua clínica, ele instala a demarcação das estruturas no âmago mesmo da experiência, no âmago do que regula seu desenvolvimento" (Leguil, 1989, p. 62).

O campo inaugural da investigação freudiana é a neurose. A histeria, especificamente, configurou-se como o paradigma teórico-clínico para a abordagem dos sintomas obsessivos e fóbicos, como também da psicose, especificamente a paranóica. Freud desmistificou (por meio de observações clínicas e teorizações sob os mesmos dados) o ponto de vista de que nenhuma sintomatologia definida poderia ser atribuída à histeria simplesmente porque nela pode ocorrer qualquer combinação de sintomas e a exagerada importância dada à simulação em seu quadro clínico.

Ainda muito influenciado por Charcot e seu ímpeto nosográfico, Freud (1888/1996) chega a escrever que deve-se contentar em definir a neurose, especificamente a histeria, a partir do aspecto puramente nosográfico, ou seja, pela totalidade dos sintomas que ela apresenta. Apesar dessa afirmação, o próprio Freud não se contentou em ficar na franja dos fenômenos da histeria. Aos poucos, foi rompendo com a apresentação dos fenômenos físicos da histeria realizados por meio dos exames semiológicos extensos nos moldes de Charcot. A abordagem puramente fenomenológica da doença tornou-se um fato incômodo para Freud em seu esforço inicial de teorizar a histérica; um mal-estar proveniente da impossibilidade de estabelecer articulações inteligíveis sobre os aspectos da histeria. 
Desse modo, o descritivismo demasiado sempre foi ponto questionável em seu esforço de desenvolver uma teoria psicopatológica. Como exemplo, apontamos a posição de Freud em relação aos ataques histéricos. Freud afirmava que ainda não existia uma teoria dos ataques histéricos. O que se tinha era apenas uma descrição desses ataques, feita por Charcot. O grande ataque histérico, segundo Charcot, compõe-se de quatro fases: (1) fase epileptóide, (2) fase dos grandes movimentos, (3) fase das "attitudes passionnelles", (4) fase do delírio terminal. Para Freud, abordar apenas o aspecto descritivo dos ataques histéricos seria insuficiente. Em suas palavras: "a descrição não projeta nenhuma luz sobre alguma conexão que possa haver entre as diferentes fases, sobre a importância dos ataques no quadro geral da histeria, ou sobre a maneira como os ataques são modificados em cada paciente" (Freud, 1892/1996, p. 89).

$\mathrm{Na}$ tentativa de ultrapassar o sensualismo do descritivismo puro, Freud procura abordar o problema dos ataques histéricos segundo outro critério, diferente do descritivo proposto por Charcot; os ataques histéricos eram investigados por Freud por meio da sugestão hipnótica e, desse modo, investigando seus processos psíquicos durante $O$ ataque. $O$ ponto central do ataque histérico seria a lembrança de uma cena significativa para o desencadeamento da doença.

É impressionante como em seus textos ditos pré-psicanalíticos, Freud sugere que a descrição dos sinais e sintomas observáveis da doença, especialmente da histeria, não ocuparia um lugar de relevância na construção do diagnóstico:

Aquilo que popularmente se descreve como temperamento histérico - instabilidade da vontade, alterações do humor, aumento da excitabilidade com diminuição de todos os sentimentos altruísticos - pode estar presente na histeria, mas não é absolutamente necessário para seu diagnóstico (Freud, 1888/1996, p. 35).

Sabemos que a clínica freudiana se assentou na questão da neurose. Mesmo estando suas pesquisas voltadas para a problemática da histeria, numa fase inicial da construção da teoria psicanalítica, Freud também já se ocupava da questão das psicoses. A preocupação de Freud em demarcar uma teoria explicativa para a experiência psicótica acompanha o ineditismo da psicanálise: "Seu interesse pela psicose, nos momentos mais iniciais de sua produção teórica, pode ser considerado, portanto, tributário desse interesse peculiar pela histeria" (Burgarelli \& Santiago, 2009, p. 144).

A princípio, a psicose, em especial a paranóia, foi estudada por Freud no campo das neuroses. Isto equivale dizer que concepções como 
recalcamento, defesa e trauma são usados para explicar o funcionamento da estrutura psicótica. O interesse de Freud pelo estudo da paranóia é elucidado por Lacan em seu Seminário sobre as psicoses (1955/2008, p. 12):

Naturalmente, Freud não ignorava a esquizofrenia [...]. Ele se interessou primeiro e essencialmente pela paranóia e para indicar-Ihes imediatamente um ponto de referência ao qual vocês poderão se reportar, lembro-lhes que no fim da observação do caso Schereber, que é o texto de maior doutrina concernente às psicoses, Freud traça uma linha divisora de águas, se assim posso me exprimir, entre paranóia, de um lado, e, de outro, tudo o que gostaria, diz ele, que fosse chamado de parafrenia, e que corresponde exatamente às esquizofrenias.

São nas cartas dirigidas a Fliess e nos correspondentes rascunhos que Freud começa a teorizar sobre o fenômeno da paranóia. Desde suas primeiras formulações, o aspecto sexual ocupava lugar de destaque na etiologia das psiconeuroses (psicose aí inclusa). No entanto, de acordo com o próprio autor, poderíamos pensar no binômio sexualidade-defesa atuando de forma conjunta como fator etiológico na produção das neuroses de defesa: "O excesso de sexualidade, isoladamente, não seria suficiente para causar recalcamento; seria necessária a cooperação da defesa; entretanto, sem um excesso de sexualidade a defesa não produziria uma neurose" (Freud, 1896/1996, p. 138).

Retomamos o Rascunho K: As Neuroses de Defesa (1894/1996), um esboço do texto sobre as Neuropsicoses de Defesa, de 1896, para exemplificarmos o caminho de diferenciação entre os fenômenos que se apresentavam na clínica. Neste texto, Freud estabelece comparações e distinções entre os tipos de neuroses de defesa: histeria, neurose obsessiva, paranóia e confusão mental alucinatória aguda, visando, desde o princípio, o diagnóstico diferencial das "neuroses".

Essas neuropsicoses seriam formas de defesa do Eu frente à idéias que lhe eram incompatíveis, sendo que a maneira como se daria o recalque sobre elas configuraria a especificidade de cada neurose. Percebe-se que neste texto Freud já apontava a neurose como forma de defesa diferente da psicose:

Em ambos os casos até aqui considerados, a defesa contra a ideia incompatível era efetuada separando-a de seu afeto; a ideia permanecia na consciência, ainda que enfraquecida e isolada. Há, entretanto, uma espécie de defesa, muito mais poderosa e bem-sucedida. Aqui, o ego [Eu] rejeita a ideia 
incompatível juntamente com seu afeto e comporta-se como se a ideia jamais lhe tivesse ocorrido. Mas a partir do momento em que o tenha conseguido, o sujeito encontra-se numa psicose, que só pode ser qualificada como 'confusão alucinatória' (Freud, 1894/1996, p.71).

Neste momento, para Freud, a defesa na neurose se daria pela separação entre uma ideia incompatível e seu afeto, permanecendo a ideia na consciência. Contudo, na psicose, o Eu rejeitaria a ideia incompatível junto com o afeto, defendendo-se desta primeira por meio de uma fuga para a psicose. Ao escapar da ideia intolerável, como se ela nunca estivesse existido, também há o afastamento, de alguma forma, da realidade, pelo fato de esta ideia estar ligada a um fragmento da mesma (Côrtes, 2010).

Desse modo, como ressalta Brepohl (2012), ao operar uma diferenciação sobre os processos dos mecanismos de defesa, Freud acaba marcando uma distinção parcial entre os dois primeiros grupos (fobias/obsessões e histeria) e uma distinção mais radical entre estes e a última (psicose alucinatória). É com base, então, no mecanismo defensivo que ele começa a esboçar um mapeamento deste campo ainda novo - a psicose - mas com o qual está buscando se familiarizar.

Freud estabelece um ponto importante na sua teoria psicopatológica que aponta para a constante busca de um diagnóstico diferencial: a diferenciação das formas de defesa, levando em consideração o afeto, o conteúdo da ideia e as alucinações, em relação à histeria, às idéias obsessivas, à confusão alucinatória e à paranóia, como pode ser observado no Rascunho H (Freud, 1895/1996).

No texto denominado Paranóia, podemos identificar tais diferenças entre as neuropsicoses: na histeria, em que a ideia incompatível não teria acesso à associação com o eu, o conteúdo estaria ausente da consciência e seu afeto eliminado por conversão. Também nas ideia obsessivas, a ideia incompatível não teria acesso à associação. 0 afeto seria conservado e o conteúdo representado por um substituto. $\mathrm{Na}$ confusão alucinatória, a totalidade da ideia incompatível (afeto e conteúdo) seria mantida afastada do eu. Isto só se tornaria possível à custa de um desligamento parcial do mundo externo, restando, portanto, o recurso às alucinações. Na paranóia, então, o conteúdo e o afeto da ideia incompatível seriam mantidos, mas projetados no mundo externo. As alucinações, que surgem em algumas formas da doença, seriam hostis ao ego, mas apoiariam a defesa.

Mesmo que as agrupasse como neuroses ou neuropsicoses de defesa, Freud, desde o princípio, percebia as diferenças entre neurose e psicose. Essa "diferença", que o obrigava a operar em um diagnóstico diferencial na clínica, pôde ser analisada no modus operandis do mecanismo de defesa na neurose e na psicose. Como aponta Brepohl 
(2012, p. 50), "percebe-se um movimento que conjuga aproximações e afastamentos no que tange às diferenças e similaridades entre o mecanismo defensivo empregado pelas psicoses e pelas neuroses".

O que está em jogo aí é a diferença estrutural entre neurose e psicose, impondo-se cada vez mais na clínica, exigindo, a cada momento, um esforço de teorização e diferenciação entre estas, ou seja, o diagnóstico diferencial. Isso pode ser melhor ilustrado a partir de um questionamento feito pelo próprio Freud na carta 125 dirigida à Fliess: "Tenho diante de mim o problema da 'escolha da neurose'. Quando é que uma pessoa se torna histérica em vez de paranóica?" (Freud, 1899/1996, p.196).

\section{Considerações finais}

Como demonstramos no desenrolar de nosso artigo, a insuficiência do descritivismo é datada antes mesmo do surgimento da psicanálise. No entanto, como nos diz Lima (2012), esse postulado ainda é a prática hegemônica hoje na formação de profissionais de saúde mental e de organização de serviços de saúde mental, o que nos leva a mais uma vez retomar o debate de seus limites.

A teoria psicanalítica de Freud é um exemplo de um verdadeiro work in progress. Suas investigações foram se conceituando gradualmente, sendo continuamente postas em questionamentos, refutadas e posteriormente resgatadas sob uma nova acepção. O caminho da construção da obra freudiana demonstra, em termos de uma abordagem do sofrimento psíquico, como o postulado descritivista é (e sempre foi) insuficiente.

Em sua sistematização inicial sobre a histeria e ainda muito influenciado pela investigação nosográfica de Charcot, Freud apontava as implicações de uma nosografia puramente descritiva que não ultrapassasse 0 plano da apresentação dos fenômenos relacionados à histeria. $\mathrm{O}$ descritivismo é a estratégia nosográfica da psiquiatria descritivista para a recusa ao debate etiológico. O DSM é seu maior expoente. Como forma de garantir uma linguagem comum e objetiva no campo do sofrimento psíquico, recorre-se a uma descrição minuciosa e isolada da patologia em detrimento de teorizações causais.

A dimensão sintomatológica dos quadros psicopatológicos não pode ser pensada livre de compromissos teóricos e explicativos (trecho reformulado) ao passo que a consequência de uma descrição objetiva de um repertório de sintomas é justamente o esmaecimento das diferenças estruturais. Se é no âmago das distinções das estruturas clínicas que se opera um diagnóstico diferencial, o descritivismo, então, inviabilizaria o estabelecimento desse diagnóstico diferencial, tão caro à clínica psicanalítica e que, desde o início, aprendemos com 
Freud.

\section{Referências}

Asociación Psiquiátrica de América Latina. (2003). Guía Latinoamericana de Diasgnóstico Psiquiátrico. Recuperado em 12 de novembro de 2015 de http://www.sld.cu/galerias/pdf/sitios/desastres/guia_latinoamer ticana diagn psiq gladp.pdf

Álvarez, J., Estéban, R., \& Sauvagnat, F. (2004). Fundamentos de Psicopatologia Psicoanalítica. Madrid: Editorial Sintesis.

American Psychiatric Association (2002). Manual Diagnóstico e Estatístico de Transtornos Mentais IV-TR. Porto Alegre: Artes Médicas.

American Psychiatric Association (2014). Manual Diagnóstico e Estatístico de Transtornos Mentais V. Porto Alegre: Artes Médicas.

Aragona, M. (2009a). The Role of Comorbidity in the Crisis of the Current Psychiatric Classification System. In Philosophy, Psychiatry, \& Psychology, 16(1), p. 1-11. Recuperado em 08 de novembro de 2015 de http: //muse.jhu.edu/login?auth=0\&type=summary\&url=/journ als/philosophy_psychiatry_and_psychology/v016/16.1.aragona. html

Aragona, M. (2009b). About and Beyond Comorbidity: Does the Crisis of the DSM Bring on a Radical Rethinking of Descriptive Psychopathology? In Philosophy, Psychiatry \& Psychology, 16(1), p. 29-33. Recuperado em 08 de novembro de 2015 de http: // muse.jhu. edu/login?auth=0\&type=summary\&url=/journ als/philosophy_psychiatry_and_psychology/v016/16.1.aragona 01.pdf

Aragona, M. (2014). Epistemological refl ections about the crisis of the DSM-5 and the revolutionary potential of the RDoC project. In Dialogues Philophosy, Mental and Neuro Sciences, 7(1), p. 11-20. Recuperado em 08 de novembro de 2015 de http: //www. crossingdialogues.com/Ms-A14-08.pdf

Berrios, E. (2012a). Psicopatologia descritiva: aspectos históricos e conceituais. Revista Latinoamericana de Psicopatologia Fundamental, 15(1), 171-196. Recuperado em 28 abril de http://www.scielo.br/scielo.php?script=sci_arttext\&pid=S141547142012000100012\&lng=en\&tIng=pt. doi: 10.1590/S141547142012000100012

Berrios, E. (2012b). A psicopatologia da afetividade: aspectos conceituais e históricos. Revista Latinoamericana de Psicopatologia Fundamental, 15(1), 138-170. Recuperado em 
http: //www.scielo.br/scielo.php?script=sci_arttext\&pid=S141547142012000100011

Brepohl, D. (2012). As psicoses na obra de Freud à luz da categoria do estranho. Dissertação de Mestrado em Psicologia, Setor de Ciências Humanas, Letras e Artes, Universidade Federal do Paraná, PR, Brasil.

Burgarelli, S., \& Santiago, J. (2009). A psicose de Lacan a Freud. Arquivos Brasileiros de Psicologia, 61(1), 143-152. Recuperado em 24 de maio de 2014 de http: // www.scielo.br/scielo.php?script=sci_arttext\&pid=S141547142012000100011

Carvalho, R. (2012). Um passo adiante é um retorno às origens. Letra Freudiana, ano XI. Recuperado em 06 de junho de 2014 de http: //www.escolaletrafreudiana.com.br/UserFiles/110/File/arti gos/letra1012/038.pdf

Côrtes, C. (2010). A psicose como escolha de uma posição subjetiva: da "escolha da neurose" em Freud à estrutura e os modos de gozo em Lacan. Dissertação de Mestrado, Pontifícia Universidade Católica de Minas Gerais. Belo Horizonte, MG, Brasil.

Dunker, C., \& Kyrillos Neto, F. (2011). A crítica psicanalítica do DSMIV: breve história do casamento psicopatológico entre psicanálise e psiquiatria. Revista Latinoamericana de Psicopatologia Fundamental, 14(4), 611-626. Recuperado em 20 de abril de 2014 de http: // www.scielo. br/scielo. php?pid=S1415$47142011000400003 \&$ script $=$ sci_arttext

Frances, A. (2013). Saving normal: an insider's revolt against out-ofcontrol psychiatric diagnosis, DSM-5, big pharma, and the medicalization of ordinary life. New York: William Morrow.

Frances, A. (2014). Somos Todos Enfermos Mentales?: Manifiesto contra los abusos de la psiquiatria. Barcelona: Ariel (Traduzido por J. Paredes).

Figueiredo, A., \& Machado, O. (2000). O diagnóstico em psicanálise: do fenômeno à estrutura. Ágora: Estudos em Teoria Psicanalítica, 3(2), 65-86. Recuperado em 29 de abril de 2014 de http: //www.scielo.br/scielo.php?script=sci_arttext\&pid=S1516$14982000000200004 \&$ lng =en\&tlng=pt. doi: 10.1590/S151614982000000200004

Figueiredo, A. \& Tenório, F. (2002). O diagnóstico em psiquiatria e psicanálise. Revista Latinoamericana de Psicopatologia Fundamental, V(1), 29-43. 
Freud, S. (1892/1996). Esboços para a Comunicação Preliminar de 1893. In: Edição Standard das Obras Completas de Sigmund Freud, vol. I, p. 86-91. Rio de Janeiro: Imago.

Freud, S. (1888/1996). Histeria. In: Edição Standard das Obras Completas de Sigmund Freud, vol. I, p. 28-41. Rio de Janeiro: I mago.

Freud, S. (1899/1996). Extratos dos documentos dirigidos a Fliess: Carta 125. In: Edição Standard das Obras Completas de Sigmund Freud, vol. I, p. 196. Rio de Janeiro: Imago.

Freud, S. (1894/1996). Extratos dos documentos dirigidos a Fliess: Rascunho K. In: Edição Standard das Obras Completas de Sigmund Freud, vol. I, p. 132-138. Rio de Janeiro: I mago.

Freud, S. (1895/1996). Extratos dos documentos dirigidos a Fliess: Racunho H: Paranóia. In: Edição Standard das Obras Completas de Sigmund Freud, vol. I, p. 125-127. Rio de Janeiro: Imago.

Freud, S. (1896/1996). Extratos dos documentos dirigidos a Fliess: Carta 46. In: Edição Standard das Obras Completas de Sigmund Freud, vol. I, p. 138-140. Rio de Janeiro: Imago.

Insel, T. (2013). NIMH Director's Blog: Transforming Diagnosis. 29 April 2013. Recuperado em 08 de novembro de 2015 de http://www.nimh.nih.gov/about/director/2013/transformingdiagnosis.shtml

Kyrillos Neto, F., Silva, C., Pederzoli, A, \& Hernandes, M. (2011). DSM e psicanálise: uma discussão diagnóstica. Revista da SPAGESP Sociedade de Psicoterapias Analíticas Grupais do Estado de São Paulo, 12(2), 44-55. Recuperado em 20 de abril de http://pepsic. bvsalud.org/scielo. php?script=sci_arttext\&pid=S1 677-29702011000200006

Lacan, J. (1955/2008). O seminário. Livro 3. As Psicoses. Rio de Janeiro: Jorge Zahar.

Leguil, F. (1989). Mais além dos fenômenos. In J. Lacan et al. A querela dos diagnósticos. Rio de Janeiro: Jorge Zahar.

Lima, R. (2012). Três tópicos sobre a relação entre DSM e política. In Kyrillos Neto, F. \& Calazans, R. (Orgs.). Psicopatologia em debate: controvérsias sobre os DSMs. Barbacena: EdUEMG, p. 95-111.

López-Ibor Jr., J., \& López-Ibor, M-I. (2008). Anthropological Perspectives in Psychiatric Nosology. In Philosophy, Psychiatry \& Psychology, 15(3), p. 259-263. Recuperado em 08 de novembro de 2015 de http: //muse.jhu.edu/login?auth=0\&type=summary\&url=/journ als/philosophy_psychiatry_and_psychology/v015/15.3.lopezibor 01.pdf

Miller, J-A. (1998). Discurso do método psicanalítico. In Lacan Elucidado. Rio de Janeiro: J orge Zahar. 
Oliveira, H., \& Neves, T. (2012). O fenômeno e a estrutura: do diagnóstico desorientado ao diagnóstico orientado pela psicanálise. Cad. Psicanál.-CPRJ, 34(26), 125-143.

Pereira, M. (2001). Kraepelin e a criação do conceito de "Demência precoce". Revista Latinoamericana de Psicopatologia Fundamental, Diciembre-Sin mes, 126-129.

Pereira, M. (2002). A "loucura circular" de Falret e as origens do conceito de "psicose maníaco-depressiva". Revista Latinoamericana de Psicopatologia Fundamental, Diciembre-Sin mes, 125-129.

Resende, M., \& Calazans, R. (2013). Neurose e psicose na CID-10 e DSM-IV: o que é ignorado? Analytica, 2(3), 145-174. Recuperado em 01 de maio de 2014 de http://www. seer.ufsj.edu. br/index. php/analytica/article/viewFil e/ $467 / 463$

Sadala, G., \& Martinho, M. (2011). A estrutura em psicanálise: uma enunciação desde Freud. Ágora: Estudos em Teoria Psicanalítica, 14(2), 243-258. Recuperado em 13 de maio de 2014

de:

http: //www.scielo.br/scielo.php?script=sci_arttext\&pid=S151614982011000200006\&lng=en\&tlng=pt. doi: 10.1590/S151614982011000200006

Soler, C. (2007). A psicose: uma problemática. In: O inconsciente a céu aberto da psicose. Rio de Janeiro: Jorge Zahar.

Stagnaro, J. (2007). Perspectiva crítica de las nosografías psiquiátricas contemporâneas. In Laurent, É. (Org.). Psiquiatria e psicoanálisis. Buenos Aires: Grama.

Stangellini, G., \& Broome, M. (2014). Psychopathology as the basic science of psychiatry. The British Journal of Psychiatry, 205, p. 169-170. Recuperado em 08 de novembro de 2015 de http://bjp.rcpsych.org/content/bjprcpsych/205/3/169.full.pdf

Tucker, G. (1998). Putting DSM-IV in Perspective. In American Journal of Psychiatry, 155:2, p. 159-161. Recuperado em 12 de novembro de 2015

http://ajp. psychiatryonline.org/doi/pdf/10.1176/ajp.155.2.159

Zorzanelli, R., Dalgalarrondo, P., \& Banzato, C. (2014). O projeto Research Domain Criteria e o abandono da tradição psicopatológica. In Revista Latinoamericana de Psicopatologia Fundamental, 17(2), p. 328-341. Recuperado em 12 de novembro de https://dx.doi.org/10.1590/1984-0381v17n2a12

\section{Endereço para correspondência Samira Pontes Universidade Federal de São J oão del Rei Praça Dom Helvécio, 74, Fábricas, CEP 36301-160, São J oão del Rei - MG, Brasil Endereço eletrônico: spcpontes@gmail.com}

\section{Roberto Calazans}


Universidade Federal de São J oão del Rei

Praça Dom Helvécio, 74, Fábricas, CEP 36301-160, São J oão del Rei - MG, Brasil

Endereço eletrônico: roberto.calazans@gmail.com

Recebido em: 11/02/2015

Reformulado em: 18/11/2015

Aceito para publicação em: 16/12/2015

\section{Notas}

* Mestranda do Programa de Pós-Graduação em Psicologia da Universidade Federal de São J oão del Rei (UFSJ). Bolsista CAPES.

** Doutor em Teoria Psicanalítica pela Universidade Federal do Rio de Janeiro (UFRJ). Professor Associado II da Universidade Federal de São João del Rei (UFSJ) e do Programa de Pós-Graduação em Psicologia da Universidade Federal de São João del Rei (UFSJ). Bolsista de Produtividade em Pesquisa nível 2 CNPq. Psicanalista.

1 Jean-Pierre Falret, como um representante da nosologia clássica francesa, foi reponsável pela definição de uma nova forma clínica da alienção mental: a "loucura circular" constitui uma doença mental com quadro clínico e evolução bem delimitadas e específicas. A postura psicopatológica de Falret contribui decisivamente para o declínio da noção de alienação mental, abrindo o espaço para o conceito de "entidade mórbida" e de "doença mental", que seria amplamente desenvolvido no contexto alemão pela nascente nosografia kraepeliniana (Pereira, 2002, p. 128). 